\title{
ADAPTACIÓN DE \\ UNOS DRAMAS \\ DE HROTSVITHA \\ TRADUCIDOS POR \\ LUIS ASTEY \\ Marcel Sisniega*
}

A mediados de 1900 recibí la invitación de un grupo de alumnos del Centro Universitario de Teatro para dirigir una puesta en escena. Acepté gustoso, preguntándome cuál sería el texto más adecuado para estos jóvenes actores.

Afortunadamente, había caído en mis manos la traducción recién publicada de Luis Astey sobre los dramas de la monja Hrotsvitha de Gandersheim. Aunque los textos originales, escritos en latín medieval, no eran precisamente ligeros ni fáciles de representar, me pareció notable que Astey ofreciera al mundo de habla hispana obras tan singulares.

De la vida de Hrotsvitha poco se sabe. Algunos estudiosos le atribuyen un linaje aristocrático, acaso perteneciente al ducado de Rossov. Hacia el año de 955 se le encuentra en la Abadía de Gandersheim, donde estudió con la maestra Rikardis y con Gerberta, sobrina del rey Otón. Gracias a la reforma de la vida monástica, en Gandersheim se cursaba un plan de estudios exigente, comparable con el de Cluny.

Además de siete obras dramáticas, Hrotsvitha escribió un elogio del Rey Otón y un conjunto de poemas satíricos y religiosos, entre ellos la primera versión conocida de la leyenda de Fausto. Pero si a primicias vamos, Hrotsvitha ocupa un lugar excepcional en la historia de la literatura,

* Dramaturgo mexicano. 
MARCEL SISNIEGA

puesto que fue la primera mujer en escribir teatro; el primer dramaturgo cristiano, y el primero después de la caída del Imperio romano de Occidente, es decir, luego de un silencio teatral de más de cinco siglos.

Para la puesta en escena del Centro Universitario escogí dos obras que, a mi juicio, tienden un puente entre la fe profunda de finales del primer milenio y la zozobra espiritual de nuestros tiempos. No obstante, los textos se encontraban cargados de razonamientos escolásticos y hubo que adaptarlos para llegar a una versión actoral. En este sentido, conté con la mejor ayuda de la que puede disponer un dramaturgo: el proceso de ensayos. Las improvisaciones aclaran la línea dramática y ponen de manifiesto la necesidad de abreviar o dilatar determinada situación.

Durante las investigaciones emprendidas, me atrajo cada vez más la vida de Hrotsvitha. Cómo mantuvo su fe en medio de las turbulencias de la corte de Otón y Adelaida, pero sobre todo, cuando las noticias llegadas de Roma hablaban de un Papa ruin y disoluto.

La tarea de escribir una obra mientras se la dirige no es lo más saludable para los nervios. Algunas escenas avanzan con rapidez y otras parecen atorarse. Sin embargo, los frutos son alentadores porque el texto incorpora el sentir profundo de los actores.

Al cabo de seis meses de ensayo teníamos un texto renovado y una puesta en escena. A mil años de distancia, Hrotsvitha de Gandersheim se disponía a presenciar sus obras.

Durante nuestra temporada tuve el agrado de conocer a Luis Astey, quien asistió a una función en el Teatro Juan Ruiz de Alarcón y departió largamente con los alumnos. Recuerdo que el maestro Astey se mostraba complacido de presentar un montaje a escasos meses de la publicación de un libro que él consideraba primordialmente de índole académica. Recuerdo, también, su aprobación de las libertades que habíamos tomado respecto a las obras originales para la puesta en escena.

Siempre he lamentado el no haber incluido un agradecimiento al maestro Luis Astey en el programa de mano. Aunque tardío, vaya ahora un cálido agradecimiento al hombre que dedicó años de estudio a sacar del olvido a nuestra admirada Hrotsvitha. 


\section{HROTSVITHA I}

Hrotsvitha de Gandersheim

Reina Adelaida de Sajonia

Rey Otón de Sajonia

Liudbrando, consejero real

Papa Juan XII, Obispo de Roma

Abadesa Gerberta, sobrina de Otón

Maestra Rikardis

Diablo

Nótker Labeo y Rábano Mauro, sabios de la época

Soldados Ansfrid y Gotfrid

Secuaz de Juan XII

Amante de Juan XII

Marido de la amante

Príncipe Ludolfo, hijo de Otón

Berenguer, Rey de Italia

\section{Castillo de Hrotsvitha}

Hrotsvitha lee el Evangelio de San Juan. Entra Gotfrid, escudero del Duque.

GOTFRID: Hrotsvitha...

HROTSVITHA: ¿Qué ha ocurrido?

GOTFRID: Nos emboscaron, perdimos muchos hombres.

HROTSVITHA: ¿Y mi padre, mis hermanos?

GOTFRID: $\quad$ El Rey Otón les ofreció clemencia, pero se negaron a rendirse.

HROTSVITHA: Así, tan de repente, una frase común anuncia la muerte.

GOTFRID: Fortaleza, doncella. Deja obrar al tiempo. 
MARCEL SISNIEGA

HROTSVITHA: Tiempo quisiera yo para ellos.

GOTFRID: De no ser por Adelaida, vivirían.

Hrotsvitha: En los últimos meses, se habló demasiado de la reina y muy poco de la muerte.

GOTFRID: Honremos la memoria de tu padre.

HROTSVITHA: Su causa valía menos que él.

GOTFRID: Quizá tengas razón. Pero el Rey Otón es benévolo, firme, y sabrá atajar las ambiciones de Adelaida.

HROTSVITHA: Y mientras, ¿qué haré sola, a orillas de esta tierra congelada?

GOTFRID: $\quad$ El Duque de Baviera te ofrece asilo.

HROTSVITHA: No veré la estéril rebelión desde otra torre.

GOTFRID: El Rey Otón podría ayudarte.

HROTSVITHA: ¿Acudir al asesino de mi padre?

GOTFRID: No es deshonra aceptar la clemencia de un rey tan grande.

HRotsvitha: Retírate. Déjame sola. (Gotfrid sale) Debiera rezar, debiera percibir el vuelo rumoroso de sus almas y lo que se esfuerzan por decirme. Pero sólo veo un camino cenagoso, la noble sangre encharcada, y más allá, un cadáver fofo, de mirada simple, como extrañado por el vuelo razante de los buitres. Hermanos, quién lo dijera. Aquí jugábamos a los reyes. Y tú, padre, ¿dónde te has ido? Dime que no pasas un frío atroz, déjame saber si tu muerte es preferible a esta vida.

\section{Corte de Sajonia}

Otón y Adelaida.

OTÓN: Mientras nos roemos las vísceras, los húngaros han cruzado el Danubio y amasan un ejército enorme en la frontera. 
DRAMAS DE HROTSVITHA

ADELAIDA: Es imperioso forjar una alianza.

OTÓN:

He tendido mi mano a los duques en rebeldía, pero me exigen una declaración tuya a favor de Ludolfo.

ADELAIDA: Conoces mi parecer. Ludolfo es indigno de sucederte.

OTÓN: Aseguran que has conspirado.

ADELAIDA: ¿Hasta cuándo cesarán los infundios? Hablan mal de mí porque soy extranjera, y por las propias insidias de Ludolfo.

OTón: ¿Es verdad que les ofreciste tierras a cambio de su apoyo?

ADELAIDA: Otón, si me crees capaz, renunciaré a mis hijos, a mis pocos bienes, y me consagraré por entero al Señor.

OTóN: No, Adelaida.

ADELAIDA: Que lo sostengan delante de mí.

OTÓN: $\quad$ Seamos condescendientes.

ADELAIDA: Pero sin chantaje, sin mentiras.

OTÓN:

Adelaida, te lo suplico. Aclárale a esos duques que no pretendes usurpar el trono.

ADELAIDA: Soportaré esta humillación. Todo sea por derrotar a los húngaros y extender los límites de la cristiandad.

\section{A las puertas del Castillo de Otón}

Liudbrando, en ropas de mendigo, y el guardia Ansfrid.

LIUDBRANDO: Anda, soldado, permíteme hablar con la reina.

ANSFRID: Si esperas el tiempo necesario, pueden suceder dos cosas: que te echen una moneda, o que los cuervos te saquen los ojos.

LIUDBRANDO: Por tu arrogancia, pareciera que tú solo venciste a los húngaros.

ANSFRID: ¿Tú qué sabes de la guerra? 
MARCEL SISNIEGA

LIUDBRANDO: Que se requiere prevísión e inteligencia, no bravuconerías. Vamos, te aseguro que conozco a la reina.

ANSFRID: $\quad$ Eres un crápula, un hablador. Anda, ¡vete a calentar tu agujero!

LIUDBRANDO: Con esa lengua, llegarás a obispo.

\section{Corte de Sajonia}

Adelaida y Hrotsvitha.

HROTSVITHA: ¿Me mandó llamar?

ADELAIDA: La paz del reino me ha permitido recordar a la niña escritora de otros tiempos.

HROTSVITHA: Solía usted elogiar mis torpes poemas.

ADELAIDA: Eran tiernas alabanzas al Señor. Hrotsvitha, una doncella no puede vivir en medio de la tentación.

HROTSVITHA: No se preocupe por mí.

ADELAIDA: Quien ha sufrido desea ofrecer consuelo.

HRotSVITHA: ¿Le corresponde a usted decírmelo?

ADELAIDA: ¿Por qué no? ¿Porque tu padre y tus hermanos se equivocaron al rebelarse contra el rey? Si la funesta rebelión se hubiese prolongado, ¿quién habría vencido a los húngaros?

HROTSVITHA: Lo ignoro.

ADELAIDA: No dudo que el sufrimiento te haya conminado a reflexionar.

HROTSVITHA: Demasiadas razones cruzaron por mi mente.

ADELAIDA: Un gran dolor permite ver la luz.

HRotsvitha: Para usted es diáfana.

ADELAIDA: Porque también he padecido. Cuando Berenguer me encerró en aquel castillo, escuchaba yo las voces de los santos. Provenían del agua, o del viento, y repetía yo con ellas el credo de nuestra religión. 
DRAMAS DE HROTSVITHA

HROTSVITHA: ¿Para esto me ha llamado?

ADELAIDA: Quiero tu bien.

HROTSVITHA: ¿Cómo se propone devolvérmelo?

ADELAIDA: Encaminándote al servicio del Señor.

(Liudbrando irrumpe en el salón, seguido por Ansfrid)

LIUDBRANDO: ¡Hablaré con la reina!

ADELAIDA: ¿Quién es el mendigo cuya humildad no corresponde a su condición?

LUUDBRANDO: Fui hombre de todas las causas y descubri en ellas todos los pesares.

ADELAIDA: ¡Liudbrando!

LIUDBRANDO: A tus pies. (Ansfrid se retira)

ADELAIDA: La última vez te echabas a los pies de Berenguer.

LIUDBRANDO: Le supliqué por tu libertad, pero el infame quería verte rendida.

ADELAIDA: $\quad \mathrm{Y}$ ahora, ¿tan mal recompensa el Rey de Italia a su consejero favorito?

LIUDBRANDO: Un súbdito debe lealtad a su señor, mas no la lealtad del perro al carnicero. Amenazado de muerte, huí de aquel reino corrompido. Por los caminos fui asaltado $\mathrm{y}$ apaleado por seres incapaces de raciocinio. Bien dicen que la vergüenza enseña mucho. Bajo el cielo abierto, expuesto a los elementos, decidí que sólo serviría a Dios y a su más digno representante sobre la Tierra. ¿Los iconoclastas de Bizancio? ¿La estirpe lujuriosa que medra en Roma? Nunca. Adelaida, con todo el fervor de mi arrepentimiento, pongo mis limitadas capacidades al servicio de Sajonia.

ADELAIDA: En ti ha operado el cambio. Me complace, y tu conocimiento de Italia nos será de gran utilidad.

LIUDBRANDO: Cuantos te conocen, veneran tu noble corazón.

HROTSVITHA: ¿'Me permite una pregunta? 
MARCEL SISNIEGA

ADELAIDA: El talento de Hrotsvitha se equipara a su curiosidad.

HROTSVITHA: Se dice que la Reina italiana despoja personalmente de sus joyas a las damas de compañía.

LIUDBRANDO: No se atreven a lucirlas en su presencia. Aunque esas mujerzuelas apenas merecerían el calificativo de damas.

ADELAIDA: Moderación, Liudbrando.

LIUDBRANDO: Disculpa, los crímenes y vejaciones que he presenciado me hicieron olvidar que en otras partes se observa la castidad.

ADELAIDA: Es tan fácil corromper a una muchacha.

LIUDBRANDO: La perdición quema un instante y carcome el resto de nuestros días. En fin, para una doncella en edad de profesar, sugiero la abadía de Gandersheim.

ADELAIDA: Eso quería yo decirle.

HROTSVITHA: No sé si estoy dispuesta.

LIUDBRANDO: Pregúntate primero si mereces semejante oportunidad. ADELAIDA: Liudbrando es hombre de la iglesia.

Hrotsvitha: No dudo de mí fe. Pero quisiera estudiar con los sabios de Cluny o San Gal.

90 ADELAIDA: En Rikardis hallarás a una mujer a la altura de cualquier sabio.

LIUDBRANDO: Si mis ocupaciones lo permiten, yo mismo podría impartir las clases de latín y de gramática.

HROTSVITHA: Veamos el mundo desde la abadía.

ADELAIDA: Gracias, Hrotsvitha. Me has reconfortado.

\section{Abadía de Gandersheim}

Entran Rikardis y la abadesa Gerberta.

RIKARDIS: $\quad$ Entonces, Eneas partió a fundar Roma. Dido, afligida, se clavó la espada de su amante.

GERBERTA: Eneas me recuerda a Ludolfo. 
RIKARDIS: No hay punto de comparación. Ludolfo es un guerrero desprovisto de toda causa.

GERBERTA: Maestra, ¿usted cree que podemos ser otras personas, como en los sueños?

RIKARDIS: Dios nos confirió un solo ser. (Entra Hrotsvitha)

GERBERTA: Pero por ejemplo, Hrotsvitha escribió otro poema.

RIKARDIS: Empecemos por los pasajes de San Agustín. Abadesa, ¿cómo refutó el santo padre a los maniqueos?

GERBERTA: Pues, Mani fue un hereje que se equivocó rotundamente al suponer que el mal se incrustaba como una cuña en el reino del bien.

RUKARDIS: ¿Es todo?

GERBERTA: Rikardis, me da tanto gusto que Hrotsvitha haya recobrado su alegría.

RIKARDIS: Le ruego no se aparte del tema. ¿Qué ocurriría si mañana llamara un maniqueo a la puerta y se diera a la tarea de allegarlas a su falsa religión?

GERBERTA: Le recomendaría la lectura de San Agustín.

RIKARDIS: Opinión de simples. Una abadesa no puede descuidar su cuadrivio. Y bien, Hrotsvitha, ¿de qué trata el poema?

Hrotsvitha: Es la historia de San Gandolfo.

RIKARDIS: Un tema singular. Procede a la lectura.

(Hrotsvitha y Gerberta representan el poema)

HROTSVITHA: Esta es la historia del honrado varón francés Que tuvo por esposa a una lasciva mujer. Mientras el buen Gandolfo rezaba sus matines, Moira, la pecadora, se entregaba a otros fines. Recorría el establo, y como buscando un ciprés, Se encontró de pronto con un criado descortés.

GERBERTA: Yacían en la paja, dulces y entrelazados.

HROTSVITHA: Sorprendiólos Gandolfo, quedaron demudados. El siervo dio un brinco y como era menester, 
MARCEL SISNIEGA

Gandolfo, sin enojo, expuso su entender.

"Moira del alma mía, no te puedo apartar.

Perdonaré tu falta si vuelves al hogar."

GERBERTA: "Te quiero, Gandolfo, he cometido un error, Me figuré que el criado eras tú, mi señor."

HROTSVITHA: Asunto dirimido, piensa el santo confiado, Mas Moira, en la noche, se reúne con su esclavo.

GERBERTA: Entre juramentos, ella suplica dar muerte Al honrado Gandolfo antes de que se despierte.

HROTSVITHA: Dormía el santo varón tranquilo en su aposento $\mathrm{Y}$ soñaba, sin duda, en algún sueño contento, Cuando el criado, sin mayor remordimiento Le clava un filoso puñal corazón adentro.

GERBERTA: Sepultado Gandolfo estalló un gran alborozo, Los pecadores al baile y los muertos al foso.

HROTSVITHA: A Moira, la infiel, no le atormentaban reproches, Mientras el criado arara su cuerpo cada noche.

De súbito, resonó una voz en la comarca: ¡San Gandolfo no se iba del todo con la Parca!

La grey mansa y humilde se desvive en halagos, De la tumba sagrada brotan sendos milagros. Acuden viejas, endemoniados y leprosos, Ávidos de salud, inocentes, fervorosos.

Todos por San Gandolfo sus ruegos ven cumplidos. Sólo Moira se niega a creer en su ex-marido.

$\mathrm{Y}$ en medio de un festejo lascivo, lisonjero, Mientras oye caer los chorros de dinero, Se ríe y gritonea subiéndose la falda:

"No me vengan con cuentos, ipara milagros, mis nalgas!"

Entonces, como sin querer, discreto y pudibundo, Aflora un hedor soez, digno del inframundo. 
DRAMAS DE HROTSVITHA

Los borrachos se miran, ya no chocan las copas,

Unos jalan aire, otros se tapan la boca.

Moira se contorsiona, sonríe con timidez

Quiere ocultar los hechos, la extrema fetidez.

"Fue un milagro de Gandolfo", balbucea la dama,

Pero locas carcajadas pregonan ya su fama.

$Y$ así fue como en castigo a su inclemencia,

El resto de su vida despidió flatulencias.

GERBERTA: ¿Qué opina, maestra? ¿Cree que podamos someterlo a la consideración de los sabios?

RIKARDIS: Lo dudo.

HROTSVITHA: ¿Le parece malo?

RIKARDIS: Cometes algunas imprecisiones. Esas pueden corregirse. Pero no deja de inquietarme tu propensión a los temas mundanos.

GERBERTA: Es la historia de un santo.

HROTSVITHA: Gracias a usted conocimos a Virgilio.

RIKARDIS: ¿De la Eneida a Gandolfo? Vaya humildad, Hrotsvitha. Además ¿por qué representaron el poema? La iglesia lo prohibe.

HROTSVITHA: Estamos entre amigas.

GERBERTA: Somos servidoras de Cristo.

RIKARDIS: Al ver esos movimientos, pensé que estábamos entre el vulgo.

HROTSVỊTHA: De niña presencié obras de teatro. Y ahora, al conocer las comedias de Terencio, he sentido deseos de imitarlo.

RIKARDIS: $\quad$ Escribe. No te lo impediré. Pero piensa que tus obras serán leídas, nunca representadas. Y sobre todo, han de agradar al Señor.

(Rikardis sale)

GERBERTA: Recuerda, Hrotsvitha... Leídas, nunca representadas.

(Hrotsvitha ve cruzar a los amigos de Calímaco y sale) 
MARCEL SISNIEGA

\section{CALÍMACO, UN AMOR MÁS ALLÁ DE LO DEBIDO}

Calimaco, joven romano

Andrónico, mandatario romano

Drusiana, esposa de Andrónico

San Juan

Fortunato, sirviente del mandatario

Esclava

Aparición

Amigos de Calímaco 1 y 2

Calle de una ciudad perteneciente al Imperio romano, a principios de la era cristiana

Los Amigos beben vino. Entra Calímaco.

94 CalímaCo: Amigos, necesito un consejo.

AMTGO 1: $\quad$ Estamos para ayudarte.

CALÍMACO: Durante largo tiempo he padecido un dolor atroz y espero que sus palabras me puedan aliviar.

AMIGo 1: $\quad$ Entre amigos es un deber compartir los cambios de fortuna.

CALÍMACO: Ojalá pudieran compartir mi sufrimiento.

AMIGo 2: Dinos lo que te pasa.

CALÍMACO: Estoy enamorado.

AMIGO 1: ¿De quién?

CALÍMACO: ¿Conocen a Drusiana?

AMigo 1: ¿La esposa del mandatario Andrónico?

CALÍMACO: La misma.

AMIGO 2: $\quad$ Haces mal.

AMIGO 1: Drusiana fue lavada por las aguas del bautismo. 
DRAMAS DE HROTSVITHA

Calímaco: Eso me tiene sin cuidado.

AMigo 2: $\quad$ No sabes lo que dices.

CALÍMACo: Otros han seducido a mujeres casadas.

AMIgo 2: Sí, pero Drusiana abrazó la doctrina del apóstol Juan.

Se prometió a Dios en cuerpo y alma, a tal grado que ni su marido goza ya de sus encantos.

CALÍMACO: Recurro a ustedes y lejos de ayudar, me desesperan. AMIGO 1: ¿Quieres amigos o falsos consejeros?

CALÍMACo: No los necesito. Iré con Drusiana. La perseverancia del amante vence, todos los obstáculos.

AMIGO 2: No podrás convencerla.

CALÍMACO: ¿Quién me lo va a impedir? ¿El destino? (Sale)

AMigo 1: Ya veremos. (Salen)

\section{Casa de Andrónico}

Drusiana recorre el jardín.

CALIMACO: Drusiana, permíteme una palabra.

DRUSIANA: ¿Qué se te ofrece?

CALÍMACO: ¿De verdad quieres saberlo?

DRUSIANA: Por supuesto.

CALÍMACO: Quiero hablarte de amor.

DRUSIANA: ¿De qué amor?

CALÍMACO: Del que suscitas. Te amo por sobre todas las cosas.

DRUSIANA: ¿Qué derecho, qué autoridad te permite hablarme de ese modo?

CALÍMACo: Tu belleza es mi única razón.

DRUSIANA: ¿Mi belleza?

CALÍMACO: Sí.

DRUSIANA: ¿En qué te atañe?

CAlímaco: Hasta ahora, en muy poco. Pero eso debe cambiar. 
MARCEL SISNIEGA

DRUSIANA: Aléjate, aléjate, seductor abominable. Tus palabras me confunden, me enredas con diabólicas falacias.

CAĹmACO: Drusiana, tu amor desgarra mi corazón. Correspóndeme.

DRUSIANA: De nada valen tus lascivas incitaciones.

CALÍmACO: No percibo malestar en tus palabras. Y creo que el amor empieza a ruborizarte.

DRUSIANA: Me indignas.

CALÍMACO: Ya cambiarás de parecer.

DRUSIANA: Jamás.

CALÍMACO: Eres demasiado cruel.

DRUSIANA: Loco, insensato. ¿Por qué te engañas con vanas esperanzas? ¿Qué pacto, qué demencia te hace pensar que cederé a tus levedades cuando hace mucho tiempo que no comparto la cama de mi esposo?

CALÍMACO: ¡Por Dios y por los hombres! No descansaré hasta rendirte con sutiles asechanzas. (Salen por distintos lugares)

\section{Casa de Andrónico}

Andrónico se refocila con una Esclava. Drusiana pasa cerca de ellos y luego se arrodilla en otra área de la casa.

DRUSIANA: Señor mío, Jesucristo. ¿De qué me valió someterme a la castidad si a Calímaco lo engaña mi apariencia? Atiende, por favor, a mis temores. Atiende este dolor que me consume... (El Amigo 2 susurra algo al oído de Andrónico)

ANDRónico: ¿Drusiana? (Ríe) Por favor Retírate. (Sale el Amigo 2) DRUSIANA: Si denuncio a Calímaco, se desatará un escándalo y tal vez lo maten por mi culpa. Si guardo el secreto... No, guardar semejante secreto va en contra tuya; $y$ sin ti, no podría resistir a las diabólicas insidias de Calímaco. ¿Qué debo hacer? ¿Será la muerte mi única sa- 


\section{DRAMAS DE HROTSVITHA}

lida? Si lo ordenas, moriré por ti, con tal de no ser la ruina de este joven lujurioso. (Drusiana muere de una ligera fiebre. Andrónico se acerca)

ANDRÓNICO: Drusiana... Respóndeme. ¿Qué ocurre? Drusiana, muerta. Y hace tan poco respiraba. (Entra Fortunato. Carga a Drusiana y la tiende sobre una banca, donde la amortaja la Esclava)

ANDRÓNICO: Debo hallar al santo Juan.

\section{Santuario}

ANDRÓNICO: Juan, ayúdame. Estoy harto de la vida.

JUAN:

¿Qué te aflige?

ANDRÓNICO: Drusiana, tu seguidora... Ha muerto.

JUAN:

No te lamentes. Su alma, liberada del cuerpo, se deleita en la paz celestial.

ANDRÓNICO: Quisiera creerlo, pero algo me atormenta: Drusiana se dejó morir.

JUAN: ¿Por qué lo haría? Va en contra de las enseñanzas.

ANDRÓNICO: Escuché un rumor, pero me pareció infundado.

JUAN:

Quizá el tiempo nos dé la respuesta.

ANDRÓNICO: Me atormenta el remordimiento.

JUAN:

Vamos, celebremos diligentes las exequias.

ANDRÓNICO: Dejé a Fortunato, mi sirviente, como guardián de la catacumba.

\section{Afuera de la catacumba}

Fortunato prueba su suerte. Llega Calímaco.

CALÍMACO: Fortunato, ¿qué puedo hacer? Ni la muerte apaga mi amor a Drusiana. 
MARCEL SISNIEGA

FORTUNATO: Pobre Diablo.

CALÍMACO: Moriré si no me ayudas.

FORTUNATO: ¿Pero cómo puedo ayudarte?

CALÍMACo: Déjame verla.

FORTUNATO: ¿Supones que su cuerpo aún está tibio? Una ligera fiebre no deja manchas en la piel.

CalímaCo: Dichoso de mí si pudiera poseerla.

FORTUNATO: Por una módica gratificación podrías servirte de ella.

CALímaCo: Toma, es todo lo que traigo. Después te daré más.

FORTUNATO: Vamos, entra. (Pasan a la catacumba) He aquí el cuerpo. Ni su cara se ha entumecido, ni sus miembros están rígidos. Abusa de ella libremente.

CalímaCo: Oh, Drusiana, Drusiana. Mi corazón te venera. ¿Por qué te opusiste a mis deseos? Ahora, al fin, haré contigo lo que siempre he deseado.

FORTUNATO: ¡Una serpiente! (La serpiente muerde a Fortunato que entra en agonía)

CALÍMACO: Fortunato... la serpiente... ¿Cómo puede ser? Fortunato, ¿por qué me incitaste a la profanación? Respóndeme; no te mueras todavía.

(Fortunato expira. Calímaco se vuelve y se encuentra con Jesucristo, en la figura de un joven con el rostro envuelto en llamas)

JESUCRISTO: (Una chispa salta de su rostro) Calímaco, en la muerte hallarás la vida.

(Calímaco muere. Jesucristo cubre con la mortaja el cuerpo de Drusiana y sale de la catacumba) 
DRAMAS DE HROTSVITHA

\section{Afuera de la catacumba}

Andrónico y Juan.

JUAN: $\quad$ Entremos a la catacumba para encomendar a Cristo el alma de Drusiana.

ANDRÓNICO: Nunca olvidas a tu Señor. (Aparece Jesucristo)

JESUCRISTO: Drusiana y Calímaco deben glorificar mi nombre.

JUAN:

¿Qué prodigio es éste? El Dios invisible se nos ha presentado.

ANDRÓNICO: ¿Dios? Ese no es Dios.

JUAN:

Tal vez otra señal nos ayude a comprender. (Entran a la catacumba) El sepulcro está abierto, y junto al cuerpo de Drusiana yacen dos cadáveres.

ANDRÓNICO: Un amigo de Calímaco me contó que él amaba ílícitamente a mi esposa.

JuAN: Qué sacrilegio. Pero Jesucristo anunció que debía resucitarlos.

ANDRÓNICO: Beato Juan, resucita primero a Calímaco. No sea que la resurrección conlleve algún castigo.

JUAN: Dios inabarcable, simple, incalculable. Sólo tú eres lo que eres. Sólo tú asocias cuerpo y alma en el hombre. Ordena que el al iento vuelva a Calímaco para que resucite íntegro, tal como fue, con el fin de que todos te alaben y comprendan tu poder de realizar milagros.

ANDRÓNICO: Calímaco empieza a gozar del aura vital.

JUAN: Levántate y confiesa tus faltas.

CALÍMACO: No niego haberme acercado a Drusiana con el ánimo abatido y la peor de las intenciones.

JUAN: ¿Consumaste el sacrilegio?

CALÍMACO: No me fue posible.

JUAN: ¿Qué te lo impidió? 
MARCEL SISNIEGA

ANDRÓNICO: Basta, Padre Juan. Mi espíritu no descansará hasta ver a Drusiana viva, entregada a su religión y a nuestro casto amor conyugal.

JUAN: Drusiana...

DRUSIANA: Loado seas, Jesucristo. Me has dado vida nuevamente. ANDRÓNICO: Pasaste tu último día en la tristeza y hoy resurges plena de alegría. Demos gracias al autor de toda salvación.

DRUSIANA: Venerable Juan, si has resucitado a Calímaco, purificando su amor ílícito, resucita a nuestro esclavo Fortunato.

CALÍMACO: ¡No!

JUAN:

CALÍMACO: Nadie.

JUAN: Drusiana, tu virtud logrará resucitarlo.

DRUSIANA: Divina sustancia, forma inmaterial, ordena que el calor vuelva al cuerpo de Fortunato para que nuestra triple resurrección se convierta en alabanza de la santa trinidad. Despierta, Fortunato. Rompe tus ligaduras con la muerte.

FORTUNATO: ¿No murió hace unos días?

JUAN: Ahora vive en Cristo.

FORTUNATO: Y Calímaco, ¿qué hace tan serio y compungido, cuando amaba furiosamente a Drusiana?

CALÍMACO: Renuncié al amor prohibido.

JUAN: Ya es discípulo de Cristo.

FORTUNATO: No.

JUAN:

Aunque te pese.

FORTUNATO: Si Drusiana ha resucitado y Calímaco cree en Cristo, prefiero irme de un mundo tan virtuoso. (El veneno vuelve a surtir efecto)

JUAN: $\quad$ Ay, envidia del diablo, maldad de la serpiente antigua que gime todavía por la gloria de los justos.

ANDRÓNICO: La carne se le hincha nuevamente.

JUAN: Que muera y pueble el infierno.

DRUSIANA: Es terrible. 
JUAN: $\quad$ Más terribles son la envidia y la soberbia que van siempre de la mano.

ANDRÓNICO: El infeliz ha muerto.

JUAN: $\quad$ Mereció ambas muertes. Una, por disponer vilmente del cadáver de Drusiana; otra, por odiar y maldecir a quienes lo resucitaron. Dejemos al diablo con su hijo. Celebremos a Dios, juez y señor, único que distribuye con justicia los premios y los castigos. Sean para él: la virtud, el honor, la fortaleza y el júbilo. Por los siglos de los siglos.

ToDos: Amén. 
MARCEL SISNIEGA

\section{HROTSVITHA II}

\section{Corte de Otón}

Adelaida, Otón y Liudbrando.

ADELAIDA: ¿No habrá quien ponga fin a las correrías de Berenguer? ¿Seremos tan impíos para no acudir al llamado del Obispo en Roma?

LIUDBRANDO: Aunque padecí en carne propia la saña de Berenguer, soy contrario a la idea de meter las manos al fuego por un Papa como Juan XII.

ADELAIDA: ¿LLas meterás al agua? Porque, si es preciso, armaré a mi propio ejército.

LIUDBRANDO: Adelaida, yo conozco a los romanos.

ADELAIDA: Juan XII fue elegido por las autoridades de la iglesia.

LIUDBRANDO: En un sínodo fraudulento. Entiéndanme, Juan trae la depravación en la sangre. Su abuela, Maruzia, mancilló el Vaticano, y su bisabuela, Teodora, impuso a tres de sus amantes en la silla de San Pedro.

ADELAIDA: Es joven. Merece una oportunidad.

LIUDBRANDO: Que se la dé Berenguer.

ADELAIDA: Eres demasiado rencoroso. Se acerca el milenio. Asume la talla de nuestra misión.

LIUDBRANDO: En Roma, como en Italia, todo es mezquino, voluptuoso, interesado.

OTón: Liudbrando, si Carlomagno viviera, ¿acudiría al llamado del Papa?

LIUDBRANDO: Sí, majestad.

OTÓN: ¡Marcharemos sobre Italia, contra Berenguer! 
DRAMAS DE HROTSVITHA

\section{Celda de Hrotsvitha}

Mientras Hrotsvitha escribe, se le acerca Gerberta.

Gerberta: Ya es tarde.

HROTSVITHA: Me restan algunas frases. (Gerberta sale. Llega el Diablo, vestido de fraile)

DIABLO: Léeme un poco.

HRotsvitha: Oh, Drusiana, mí corazón te venera. ¿Por qué te opusiste a mis deseos?

DIABLO: Me gusta, sigue adelante.

HROTSVITHA: ¿Quién eres?

DIABLO: El inspirador de tu más bella zozobra.

HROTSVITHA: ¿Estaría dormida la portera?

DIABLO: Para mí no hay secretos. He palpado como te deleitas en lo prohibido.

HROTSVITHA: No es verdad; cuando escribo, acallo para siempre los bajos placeres.

DIABLO: La carne y la guerra son anteriores a tus palabras. (Al fondo se distingue una batalla entre Ludolfo y Berenguer)

HROTSVITHA: Ludolfo... Berenguer...

DIABLO: ¿Sabes quién va a morir?

HROTSVITHA: No veré la sangre.

DIABLO: Escucha... (Ludolfo cae)

HROTSVITHA: Ludolfo, el hijo de Otón.

DIABLO: $\quad$ Por él peleaba tu padre. Ahora, Adelaida tiene el camino despejado. Dios la favorece, y en cambio a ti, ¿qué te da?

HROTSVITHA: La fe.

DIABLO: Una breve palabra.

Hrotsvitha: Resume todo.

DIABLO: Hrotsvitha, mira como se espesa mi barba. 
MARCEL SISNIEGA

Hrotsvitha: Vade... Vade...

DIABLO: Hazme un lugar en tu cuerpo.

HROTSVITHA: Loco lleno de muerte.

DIABLO: Hija mía, no me niegues.

HrotsvitHA: ¡San Miguel, destruye a la bestia, apaga el fulgor maligno de sus ojos!

DiABLo: Me dueles tanto.

HROTSVITHA: ¡Fuera de mí celda!

DIABLO: Vendré a reclamarte.

HROTSVITHA: Aunque me aterras, tus poderes son limitados frente al Supremo.

DIABLO: Ya me llevan, Hrotsvitha. No quisiste protegerme.

\section{Abadía de Gandersheim}

Rikardis y Gerberta.

GERBERTA: Qué dicha la suya.

104 RIKARDIS: Tengo miedo.

GERBERTA: El pastor la cuidará. Además, todos los caminos conducen a Roma.

RIKARDIS: Hablé ya con los sabios. No tardarán en emitir su docta opinión acerca de las comedias de Hrotsvitha. Cuida de ella para que no se muestre orgullosa.

GERBERTA: Le tendremos buenas noticias. Y usted, cuéntenos de todo lo que vea. (Entra Adelaida)

RIKARDIS: Peregrinas somos.

ADELAIDA: Y Hrotsvitha, ¿no sale a despedirse?

GERBERTA: Desde hace varios días reza en su celda.

ADELAIDA: Dale mi bendición.

GERBERTA: Así lo haré. Buen viaje. 
DRAMAS DE HROTSVITHA

\section{El ejército de Otón se aproxima a las murallas de Roma}

ROMANO 1: ' Son los bárbaros.

ROMANA: Parecen lobos.

ROMANO 2: Dejan sus ejércitos afuera.

ROMANA: Seremos sus vasallos.

ROMANO 1: No crean. Juan XII es muy astuto.

\section{Plaza del Vaticano}

Séquito de Otón y Adelaida.

LIUDBRANDO: (A Ansfrid) Desconfio de esta gentuza. (Sigue a los reyes y cuida sus espaldas durante la ceremonia)

\section{Basílica de San Pedro. Entran Juan XII y un Secuaz}

JUAN XII: ¿Aquella es la famosa reina Adelaida? Prefiero a las rameras de Tívoli.

SECUAZ: Ya habrá oportunidad, mi señor.

JUAN XII: Menos mal que los imbéciles trajeron sus coronas. ¿La del fondo, quién es?

SECUAZ: Alguna peregrina.

JUAN XII: Llévenmela al Palacio de Letrán, mientras ordeno al gran bobo. (Los Reyes se acercan. El Secuaz rapta a la Peregrina y vuelve a la ceremonia)

OTón: $\quad$ Obispo de Roma, Sumo Pontífice...

JUAN XII: Te recuerdo que Berenguer y su hijo siguen causando estragos en mis tierras.

OTÓN: Lo derrotamos. Huyeron en desbandada.

JUAN XII: En desbandada huyen los pájaros y luego se reagrupan. 
MARCEL SISNIEGA

OTón: Juan, te doy mi palabra. Exaltaré a la iglesia y a ti, su soberano. No bajaré la espada hasta someter a tus enemigos.

JUAN XII: $\quad$ Pasen. Por ahí están los restos de San Pedro.

ADELAIDA: ¿No se arrodilla usted?

JUAN XII: Hija mía, yo decido cuando hincarme.

ROMANO 2: ¡Váyanse!

ROMANA: ¡No los queremos!

JUAN XII: Silencio entre la grey. Romanos, extranjeros, con el poder que me confiere Dios, ordeno Emperador...

OTÓN: $\quad$...del Sacro Imperio.

JUAN XII: Del Sacro Imperio, a Otón de Sajonia, y Adelaida, la toscana.

ROMANO 3: Adelaida, ¡bendícenos!

ROMANO 4: Si eres toscana, ¡cómete al bárbaro!

JUAN XII: $\quad$ Vayamos al Palacio de Letrán. Hemos preparado un banquete para ustedes.

LIUDBRANDO: No se lo aconsejo, majestad.

OTÓN: $\quad$ Revisaré mis tropas y dormiré en el campamento.

106 JUAN XII: Nunca entenderé a los germanos. Búsqueme mañana, después del mediodía.

\section{Calles de Roma}

Adelaida, Rikardis, y un Guardia sajón.

ADELAIDA: ¿Y aquello, Rikardis?

RIKARDIS: Debe ser el Coliseo.

ADELAIDA: Cuantos cristianos partieron a la gloria desde ahí. Pero qué olor tan insalubre.

RIKARDIS: Ha comenzado el verano.

ADELAIDA: Abundan los menesterosos.

RIKARDIS: Sus limosnas los atraen. 
DRAMAS DE HROTSVITHA

ADELAIDA: Cómo no ser caritativa en la ciudad de los mártires. ROMANA: ¡Reliquias de la verdadera cruz!

RIKARDIS: Charlatanes.

ROMANO 5: ¿Quién se queda con la vieja?

ROMANO 6: Ni para un caldo.

RIKARDIS: Gleba irrespetuosa.

ADELAIDA: Tomen.

ROMANO 5: Adelaida es una santa.

ROMANO 6: Cuando se tiene, se puede dar. A mí me sobra escupitajo al rey Otón.

ROMANO 5: Te sobrará la vida para exponerla como un estúpido.

ADELAIDA: Qué hermoso es el Palacio de Letrán.

RIKARDIS: Librémonos de la turba. (Entran al Palacio)

ADELAIDA: ¿Dónde estarán las cabezas de los Apóstoles y el Arca de la Alianza?

RIKARDIS: Preguntemos.

(E1 Secuaz persigue a la Peregrina)

SECUAZ: ¡De Juan sigo yo!

PEREGRINA: Ayúdenme, soy peregrina de Umbría.

ADELAIDA: ¿Estaremos en la residencia oficial?

\section{Vaticano y Monasterio}

En la misma escena se desarrolla el Sínodo contra Juan XII y el juicio de los sabios sobre las obras de Hrotsvitha. Liudbrando participa en ambas acciones. Los Sabios cambian a Obispos en cuanto se requiere.

HROTSVITHA: ¿Y si retiramos el libro?

GERBERTA: De ninguna manera.

HROTSVITHA: Siento angustia, desașosiego. 
MARCEL SISNIEGA

GERBERTA: Tonterías, Hrotsvitha. Ya están aquí los sabios. Rábano Mauro, Nótker Labeo, y Liudbrando, les deseamos larga vida y gloria eterna.

NÓTKER: Antes de comentar la obra, conozcamos la opinión de la ilustre dramaturga.

HROTSVITHA: Soy animal capaz de aprender.

RÁBANO: ¿Lo crees o lo supones?

HROTSVITHA: Algún talento he recibido.

NÓTKER: ¿ ¿No temes ser más de lo que eres?

Hrotsvitha: Me debato entre el miedo de no ser y la alegría de lo divino.

RÁBANO: Se advierten rastros de soberbia.

LIUDBRANDO: Seamos benignos.

GERBERTA: Yo la conozco desde hace tiempo y doy testimonio de su honradez.

(Entra Otón. Los Sabios se transforman en Obispos)

OTón: Obispos del Sínodo, me abruma que Juan XII no se presente a defenderse. Exijo el máximo respeto a su investidura. Cada declaración deberá ser firmada o sustentada en pruebas fehacientes.

LIUDBRANDO: Enumeremos los cargos.

OBISPO 1: Juan XII gusta de la cacería.

LIUDBRANDO: Asentado.

OBISPO 2: $\quad$ Ordenó a un diácono en una caballeriza.

LIUDBRANDO: Asentado.

OBISPO 3: $\quad$ Lo he visto brindar por el demonio.

LIUDBRANDO: Satanería.

OBISPO 4: Copuló con Ana, la viuda, y con la concubina de su padre.

LIUDBRANDO: Al hablar de pecado, lo desenmascaramos. 
DRAMAS DE HROTSVITHA

(El Monasterio)

RÁBANO: Esta mujer borda demasiado cerca.

NÓTKER: Hrotsvitha, sé franca. ¿Sientes alguna tentación?

HROTSVITHA: En ocasiones me ruborizo.

RÁBANO: Ahí está. Vírgenes en peligro, meretrices, ¿son acaso temas, o rubores, para una canonesa apartada del mundo? Quizá podrían sugerirse en algún verso afortunado, pero nunca en comedia. ¿Cómo definió San Agustín el teatro?

NÓTKER: "Extraña demencia donde el espectador goza con los sufrimientos del autor."

GERBERTA: Rikardis nos dijo que era válido escribir obras, siempre y cuando no se representaran.

NÓTKER: Lo consultaremos.

(El Sínodo)

OTÓN: ¿No pensará venir?

LIUDBRANDO: Me informan que se encuentra en Tívoli, majestad. OTÓN: Prosigamos.

OBISPO 5: $\quad$ En nombre de Benito, que fuera su maestro, iyo acuso a Juan XII de mandarle sacar los ojos!

LIUDBRANDO: Asentado.

OBISPO 6: ¡Hizo castrar a un cura que defendía el celibato!

LIUDBRANDO: Sangre perniciosa de Maruzia.

OTÓN: Imparcialidad, Liudbrando.

(E1 Monasterio)

HROTSVITHA: Aguardamos el dictamen.

GERBERTA: Con humildad y amor cristiano lo aguardamos.

RÁBANO: Aunque desprovistas de cierto pudor, las obras manifiestan habilidades incipientes. 
MARCEL SISNIEGA

LIUDBRANDO: Hrotsvitha, no excluyas la dimensión total de los amantes.

NóTKER: Obispo Liudbrando, los monjes desconocemos esos grados de temeridad. Yo me limitaré a sugerir la inclusión de temas actuales, como la astronomía o la música.

HROTSVITHA: Enmendaré mis planas.

RÁBANO: Conclusión.

NÓTKER: Celebramos las obras.

GERBERTA: Su dictamen ha de inspiramos. (Salen Hrotsvitha y Gerberta. Las acciones vuelven al Sínodo)

OTÓN: Clausuremos nuestros difíciles trabajos.

LIUDBRANDO: Aquí se han vertido cargos que avergonzarían a gente de la farándula. ¿Dónde se ha escrito que los curas de Dios deban someterse a monstruos que son la desgracia del mundo? Emperador, los obispos emitirán su fallo y les aseguro que será unánime.

OTón: $\quad$ Cúmplase la voluntad del Clero. (Sale)

\section{Tívoli}

Juan XII y el Secuaz.

JUAN XII: Así que han puesto a su pelele y pretenden excomulgarme. Al Papa no se le excomulga. En cuanto salgan de Roma, ya veremos qué hace el monigote con la Tiara.

SECUAZ: $\quad$ Señor, ¿un poco de vino para abreviar el tedio?

JUAN XII: Vino y golfas, ¡lo mejor de Tívoli! 


\section{Bosque de Lombardía}

Rikardis vaga sola y canta.

RIKARDIS: $\quad$ Soy la oveja descarriada, el pastor me abandonó...

Berenguer, Berenguer, ya no soy tibia, Berenguer.

Ven por mí.

No te tengo miedo, Berenguer.

Tú me has de sanar

y no he de volver

a mi antigua fe...

Berenguer, Berenguer, ya no soy tibia Berenguer.

(Se interna en las sombras. Berenguer cruza el escenario y la saca muerta)

\section{Campamento de Otón}

Adelaida y Liudbrando.

ADELAIDA: ¿Qué tratas de ocultarme?

LIUDBRANDO: El cadáver de Rikardis amaneció en un prado de Lombardía.

ADELAIDA: Dios mío... El Señor ha de resarcirla. (Entra Otón) ¿Ya supiste?

OTón: Sí, Adelaida. Tenemos cercado a Berenguer. Si las cosas resultan, ese tirano no verá caer la noche.

ADELAIDA: Rezo por una paz duradera. 
MARCEL SISNIEGA

LIUDBRANDO: Todavía no. Juan XII entró a Roma, y al mando de sus turbas depuso a nuestro Papa.

ADELAIDA: ¿Por qué unos renegados han de disputarse el mundo? OTÓN: En cuanto aplastemos a Berenguer, saldremos hacia Roma. Esta vez no quedará huella del pequeño Calígula.

\section{Casa en Roma}

Juan XII le obsequia un collar a su Amante.

JUAN XII: $\quad$ Lo arranqué de un altar para ofrendarlo en otro.

AMANTE: ¿Es de oro?

JUAN XII: $\quad$ Por supuesto. Aunque no pareces muy contenta.

AMANTE: $\quad$ En estos tiempos, para ser alguien hay que poseer tierras.

JUAN XII: Las tendrás.

AMANTE: ¿Cuántas?

JUAN XII: Diez metros cada vez.

AMANTE: $\quad$ Entonces, ven. Extiende mi propiedad.

JUAN XII: Ambiciosa.

AMANTE: $\quad$ Plantaré vides. Mis hijos crecerán junto a los nobles.

JUAN XII: $\quad$ Y alabarán la memoria de su madre. (Entra el Marido)

MARIDO: ¡Y tú la maldecirás!

JUAN XII: ¿Quién se atreve a importunarme?

MARIDO: $\quad$ El pobre diablo que te matará.

JUAN XII: No, espera. Baja ese puñal.

AMANTE: Nos hará ricos. Es el Papa.

MARIDO: Me honra su visita.

JUAN XII: Ella me indujo. Repúdiala. Yo te daré muchas.

MARIDO: Un pobre no cambia su vileza por dinero.

JUAN XII: Por dinero no. Por tierras, buen hombre. 
MARIDO: Maldita rata engalanada. (Lo acuchilla) Ya no tienes tierra para regalar, ni siquiera para prestar.

AMANTE: Huyamos.

MARIDO: ¡Suéltame!

AMANTE: No seas necio. Te matarán.

MARIDO: ¿Y ese collar?

AMANTE: Tal vez compre nuestras vidas. ¡Vamos!

\section{Abadía de Ganderisheim}

Gerberta, Hrotsvitha y Liudbrando.

HROTSVITHA: Qué ironía más grande que se llamara Juan.

LIUDBRANDO: Satanás envió por él a un demonio menor.

GERBERTA: Seamos compasivos.

LIUDBRANDO: Mereció cada instante de su agonía.

GERBERTA: El Emperador y Adelaida estarán satisfechos.

LIUDBRANDO: Ha sido una gran campaña. Si no fuera por lo de Rikardis...

HROTSVITHA: Nos conmovió profundamente.

GERBERTA: A toda hora rezamos por ella.

HROTSVITHA: ¿Es verdad que se perdió en un extraño desvarío?

LIUdBRANDO: Adelaida no lo sabe. Pero sí, es verdad.

GERBERTA: Me niego a creerlo. La maestra era toda dulzura, y aunque rigurosa, nos instruyó siempre con afecto memorable.

HROTSVITHA: ¿Qué planes tiene ahora, Liudbrando?

LIUDBRANDO: El Emperador me envía a una embajada en Constantinopla.

HROTSVITHA: ¿Tratará con los apóstatas?

LIUDBRANDO: Les inculcaré un poco de cultura.

GERBERTA: Debe de ser maravilloso. 
MARCEL SISNIEGA

LIUDBRANDO: A estas alturas, empiezo a pensar que el mundo es el mismo en todas partes: rufianes gobernados por imbéciles, prostitutas encubriendo a santurrones, obispos rebajados por monjes hipócritas... La enfermedad cambia de nombre, pero nunca de apellido.

Gerberta: Aquí viene Adelaida.

HROTSVITHA: A su regreso, venga a visitarnos.

LIUDBRANDO: Emperatriz, cuando usted disponga.

ADELAIDA: Permítanme hablar a solas con Hrotsvitha.

GERBERTA: Por supuesto. (Salen Gerberta y Liudbrando)

ADELAIDA: Caridad y vanidad. Dos extremos resumen nuestras vidas.

Hrotsvitha: Ciertamente.

ADELAIDA: ¿Aún me guardas rencor?

Hrotsvitha: Ya no, Adelaida.

ADELAIDA: Dame la mano. He de confesarte que ignoraba yo los muchos males que cimbran a la iglesia.

HROTSVITHA: Es preferible hablar de los primeros santos.

ADELAIDA: Se requieren obras, obras de nuestro tiempo.

114 Hrotsvitha: Cada quien emplea el talento que le fue otorgado.

ADELAIDA: En los años venideros me dedicaré a fundar hospitales y abadías.

HROTSVITHA: Los pobres se lo agradecerán.

ADELAIDA: Mañana, o dentro de algunos años, habremos de rendir cuentas al Señor. Sería tan hermoso que nos presentásemos juntas ante el Tribunal Supremo.

HROTSVITHA: ¿Desea que la acompañe a fundar monasterios?

ADELAIDA: Estás llamada a cumplir con otra empresa.

Hrotsvitha: ¿Cuál?

ADELAIDA: Escribir la historia de Otón: sus conquistas, su destino bienaventurado.

HROTSVITHA: Ya lo hizo Liudbrando.

ADELAIDA: Esas descripciones de Berenguer y Juan XII parecen sacadas de un albañal. Hrotsvitha, la Emperatriz te 10 
DRAMAS DE HROTSVITHA

suplica. Requerimos del testimonio inmaculado de una monja.

HROTSVITHA: Yo quisiera, pero no me siento capaz.

ADELAIDA: ¿Te niegas a servir al Sacro Imperio?

HrotsvithA: Vivo alejada de los grandes acontecimientos. No soy más que una despreciable imitadora de Terencio.

ADELAIDA: En Roma vimos muchos Terencios, y la maestra Rikardis se arrepintió de sus lecciones.

HROTSVITHA: No diga eso.

ADELAIDA: Además, tuve ocasión de leer tu libro.

HROTSVITHA: ¿Conoce el dictamen de los sabios?

ADELAIDA: Respeto sus opiniones pero no las comparto. Algunas proceden del ánimo varonil, y otras del entusiasmo por lo nuevo. Hrotsvitha, como mujer que conoce sus limitaciones, exijo mayor recato en lo que escribas.

HROTSVITHA: Empobreceria las obras.

ADELAIDA: La pobreza enaltece.

HROTSVITHA: Adelaida, si las obras inducen al mal, es para conocer la gloria del Supremo, que combate y aniquila a los demonios.

ADELAIDA: ¿Qué has dicho?

HRotsvitha: Debemos conocer el mal para conocer el bien. Así lo hizo San Agustín, y San Benito...

ADELAIDA: Ellos vencieron a las tentaciones. En cambio tú, extraes un no sé qué de placer oculto. Entiende, Hrotsvitha, estás llamada para una tarea encomiable: purificar tu pensamiento mientras dejas testimonio de los últimos años del hombre sobre la Tierra.

HROTSVITHA: Preferiría acompañarla a fundar monasterios.

ADELAIDA: Acabas de decirlo: cada quien deberá emplear el talento que le fue otorgado.

Hrotsvitha: El mío se limita a la poesía y al teatro. Desconozco de sínodos, de pactos y de la guerra. 
MARCEL SISNIEGA

ADELAIDA: ¿Piensas acudir ante Dios con dos libros que rayan en lo pagano? De ser así, ¿qué le dirás?

HROTSVITHA: Que fui una desdichada en busca de alegría.

ADELAIDA: En esta obra culminante hallarás todos los bienes.

Hrotsvitha: Si llego a terminar, la Gesta Ottonis será lo último que escriba.

ADELAIDA: Entonces, ¿aceptas el compromiso?

HROTSVITHA: Haré lo que usted me pida.

ADELAIDA: Tendrás varios copistas a tus órdenes.

HROTSVITHA: Se lo agradezco en el alma.

ADELAIDA: ¿Puedo sugerirte el principio?

HROTSVITHA: Ya sé cómo empezar:

“...Y vi a los muertos, grandes y pequeños, delante de Dios. Y fueron abiertos los libros. $Y$ fue abierto el libro de la vida. Y los muertos fueron juzgados por las cosas escritas en los libros, según sus obras."

ADELAIDA: Me complace, Hrotsvitha, me complace.

116 (Hrotsvitha queda sola. Ve entrar a los Anacoretas de "La conversión de Taidé", y sale lentamente de escena) 


\section{LA CONVERSIÓN DE TAIDÉ}

Taidé, meretriz

Padre Pafnucio, anacoreta del desierto

Padre Antonio

Pablo el ciego, y Simón, discípulos de Antonio

Abadesa del desierto

Jóvenes 1 y 2

Músicos, Clientes y Meretrices

\section{Desierto de la Tebaida}

Antonio, Simón y Pablo el ciego, se sientan en semicírculo. Llega Pafnucio.

ANTONIO: Pafnucio, ¿por qué sombrío y no sereno como de costumbre?

PAFNUCIO: Los hombres desacatan la voluntad divina.

ANTONIO: ¿En qué principio debe sustentarse la relación de los hombres con Dios?

PAFNUCIO: En la armonía.

ANTONIO: ¿Por qué se nos dificulta?

PAFNUCIO: Estamos formados por dos partes contradictorias.

SIMÓN: No entiendo.

PAFNUCIO: Cuerpo y alma.

PABLO: $\quad$ Son irreconciliables.

PAFNUCIO: No siempre. La música nos enseña como la armonía nace de la concordancia entre sonidos graves y agudos.

SIMÓN: ¿Cuántos tipos de música hay?

PAFNUCIO: Tres. La divina, la humana y la instrumental.

PABLO: ¿Dónde se genera la música divina? 
MARCEL SISNIEGA

PAFNuCIO: En los siete planetas y en el cielo.

PABLO: ¿El cielo y los planetas emiten sonidos?

PAFNUCIO: Un sonido inconmensurable.

SIMÓN: ¿Por qué no se oye?

PAFNUCIO: No cabe por los estrechos conductos del oído humano. ANTONIO: El sonido celestial es tan dulce, que si los hombres lo escucháramos, nos olvidaríamos de nosotros mismos y deambularíamos sin cesar de Oriente hasta Occidente.

SIMÓN: Qué bueno que no lo oímos.

PABLO: $\quad$ Y la música humana, ¿dónde se halla?

PAFNUCIO: En el cuerpo y en el alma. Pero, además, la armonía se aprecia en la voz, en el pulso de las venas, y en la perfecta distancia que separa las falanges en nuestros dedos.

Simón: $\quad$ No alcanzo a comprender tu discurso.

PABLO: A mí me asusta, sobre todo al recordar la máxima del apóstol: los necios confundirán a los sabios.

PAFNUCIO: Lo que ofende a Dios no es el conocimiento, sino la injusticia.

118 ANTONIO: Hablaste de un agravio al Creador.

PAFNUCIO: Sí. Una mujer impúdica habita en el país.

SIMón: ¿Cómo se llama?

PAFNUCIO: Taidé.

PABLO: La conocemos.

PAFNUCIO: Legiones de fornicarios acuden a ella.

ANTONIO: Así se pierden los hombres.

PAFNUCIO: Ciegos del corazón y enloquecidos, se disputan a golpes sus favores. La sangre de los rijosos mancha los umbrales del lupanar.

ANTONIO: Un vicio engendra otro.

PAFNUCIO: ¿Me comprenden ahora?

ANTONIO: Nos unimos a tu pena.

PAFNUCIO: He pensado en disfrazarme de amante, y a solas con Taidé, intentar disuadirla de su lascivia. 
DRAMAS DE HROTSVITHA

SIMÓN: $\quad$ Un plan audaz, Padre Pafnucio.

PAFNUCIO: Ayúdenme con sus plegarias.

ANTONIO: Quien derribó al Tenebroso ha de darte la victoria.

\section{Plaza de la ciudad}

Pafnucio y dos Jóvenes disolutos.

JOVEN 1: ¡Un extranjero!

JOVEN 2: ¿A quién buscas?

PAFNUCIO: Es un secreto.

JOVEN 1: $\quad$ Pues dilo.

PAFNUCIO: Se ofenderían.

JOVEN 2: ¿Nosotros?

PAFNUCIO: Busco a una mujer bella y lujuriosa.

JOVEN 1: ¿Cuál de todas?

PAFNUCIO: Taidé.

JOVEN 2: $\quad$ Ella es el fuego en el que arden los nuestros.

PAFNUCIO: ¿Dónde vive?

JOVEN 1: En aquella casa.

\section{Prostíbulo}

Entran Músicos, Clientes y Mujeres. Pafnucio busca a Taidé. Entra una mujer cubierta con un velo. Baila al son de la música. Repentinamente, la mujer se descubre y se dirige a Pafnucio.

TAIDÉ: ¿Quién eres?

PAFNUCIO: Un enamorado.

TAIDÉ: $\quad$ Quien siembre amor en mí, cosechará mi amor.

PAFNUCIO: Taidé, tras un camino largo, al fin puedo contemplar tu rostro. 
MARCEL SISNIEGA

TAIDÉ: $\quad$ Ni escondo el cuerpo ni rehuyo la plática.

PAFNUCIO: Nuestra conversación ansía un lugar más reservado.

(Salen todos menos Pafnucio y Taidé)

TAIDÉ: $\quad$ Este cuarto es cómodo y propicio para amarnos.

PAFNUCIO: Preferiría algo más íntimo.

TAIDÉ: $\quad$ Hay un lugarcito tan secreto que sólo Dios y yo sabemos de su existencia.

PAFNUCIO: ¿A qué Dios te refieres?

TAIDÉ: Al verdadero.

PAFNUCIO: ¿Aquel que todo lo sabe?

TAIDÉ: $\quad$ Pues sí, nada se le oculta.

PAFNUCIO: $\quad Y$ entonces, ¿ignora la maldad de los hombres o simplemente aplaza la hora de la justicia?

TAIDÉ: $\quad$ Supongo que pondrá en la balanza los méritos de cada uno, y a cada quien le dará su recompensa o su castigo... ¿Por qué mudas de color y te estremeces?

PAFNUCIO: Me horroriza tu descaro. A sabiendas de la verdad, TAIDÉ: $\quad$ ¡Infeliz de mí!

PAFNUCIO: A mayor temeridad, más justo será el castigo.

TAIDÉ: ¿Por qué me fustigas?

PAFNUCIO: Sobre ti pende el castigo de la gehena. Ah, si el temor sacudiera hasta el fondo tus entrañas.

TAIDÉ: ¿Qué puedo hacer?

PAFNUCIO: Desprecia el siglo. Rechaza la cópula con tus lascivos amantes.

TAIDÉ: ¿Y después?

PAFNUCIO: $\quad$ Retírate a un lugar oculto, donde puedas meditar y lamentar tus graves faltas.

TAIDÉ: $\quad$ En mí sólo reina la amargura y un terror incipiente, la conciencia de mis culpas. 
PAFNUCIO: De las espinas taladas de los vicios ha de brotar la tierna rama del arrepentimiento.

TAIDÉ: $\quad$ Si creyeras en mí, si concedieras la menor esperanza de que yo, la despreciable, la inmunda, la manchada por miles de poluciones, aún pudiera merecer el perdón...

PAFNUCIO: El Señor te dará fuerzas.

TAIDÉ: Déjame reunir mis tesoros mal habidos.

PAFNUCIO: ¡Despreocúpate de banalidades!

TAIDÉ: $\quad$ No es por conservar las joyas, ni para obsequiarlas a mis amantes. Tampoco las daré a los pobres porque las obtuve por medios indignos.

PAFNUCIO: ¿Qué harás con las joyas?

TAIDÉ: $\quad$ Entregarlas al fuego.

PAFNUCIO: $\quad$ Y pensar que hace poco te inflamabas de amor ílícito y ardias en la codicia.

TAIDÉ: $\quad$ Tal vez aún pueda enmendarme. (Sale)

\section{Calle de la ciudad}

Pafnucio ora. Llega Taidé.

TAIDÉ: Padre Pafnucio, vengo dispuesta a seguirte.

PAFNuCiO: Como tardabas, pensé que habías vuelto al siglo.

TAIDÉ: $\quad$ No temas. Sólo quemé las joyas y renuncié abiertamente a mis amantes.

PAFNUCIO: Si renunciaste a los fornicarios, puedes unirte al Amante Supremo.

TAIDÉ: Haré lo que tú me ordenes.

PAFNUCIO: Por ahora, sígueme.

TAIDÉ: Seguiré tus pasos. Ojalá pudiera continuar tus obras. 
MARCEL SISNIEGA

\section{Convento}

La Abadesa, con una vela encendida en la palma de la mano.

PAFNUCIO: La Abadesa sale a vernos.

(Pafnucio apaga la vela con su mano)

ABADESA: Bendito seas, venerable Pafnucio. ¿Por qué te has dignado visitar nuestra casa?

PADRE: Traigo a esta pequeña cabra semiviva, arrancada recientemente a los lobos. Te pido que la cuides hasta que luzca piel de oveja.

ABADESA: Explícame.

PAFNUCIO: Llevó vida de meretriz.

ABADESA: Es lamentable.

PAFNUCIO: Con ayuda de Cristo, renunció a la voluptuosidad.

ABADESA: Demos gracias al Señor.

PAFNUCIO: Apartemos a esta muchacha de las turbulencias mundanas confinándola en una celda.

ABADESA: $\quad$ El aislamiento le será de provecho.

(La Abadesa llama a una Monja, que coloca la celda de Taidé. Luego la Abadesa cambia el vestido de Taidé por un sayal, y le corta el cabello)

PAFNUCIO: Las faltas graves exigen graves correctivos.

ABADESA: Es verdad.

PAFNUCIO: Si pasara un hombre, ella podría caer nuevamente en tentación.

PAFNUCIO: Taidé, entra al aposento donde llorarás tus perversiones.

TAIDÉ: $\quad$ Es oscuro y estrecho, demasiado incómodo para una mujer endeble.

PAFNUCIO: ¿Por qué difamas tu celda? ¿Por qué te asustas? 
DRAMAS DE HROTSVITHA

TAIDÉ: $\quad$ No tengo miedo ni pretendo rebelarme, pero mi frágil cuerpo no soportará cierto inconveniente.

PAFNUCIO: ¿Cuál?

TAIDÉ: Qué mayor inconveniente que satisfacer en un mismo sitio las diferentes necesidades del cuerpo.

PAFNUCIO: $\quad$ El hedor disipará la dulzura de tus deleites perversos.

TAIDÉ: $\quad$ No me niego a vivir en este agujero, pero me duele que no haya un sitio apropiado para rezar.

PAFNUCIO: ¿De dónde sacas tú la confianza para invocar con labios mancillados el nombre del Señor?

TAIDÉ: ¿Cómo seré perdonada si me prohibes invocar al testigo de mis pecados, al único que puede escuchar mi súplica?

PAFNUCIO: No reces con palabras. Reza con llanto. Ruge desde el fondo de tu corazón atribulado.

TAIDÉ: ¿Rezar sin palabras?

PAFNuCio: Con la humildad llegará el perdón. Y en tanto, repite solamente: Creador, ten piedad de mí.

TAIDÉ: $\quad$ Necesito de tu misericordia para no doblegarme.

PAFNUCIO: Lucha con todas tus fuerzas.

TAIDÉ: Reza por mí.

PAfNucio: Así lo haré. (Esparce sal en torno de la celda) Te encomiendo a la prisionera. Amonesta su alma cuando lo juzgues conveniente.

ABADESA: Cuidaré de ella con afecto maternal.

\section{Ermita en el desierto}

PAFNUCIO: Han transcurrido tres años desde el encierro de Taidé. (Llegan Antonio, Pablo y Simón)

ANTONIO: Se cumplió la promesa. 
MARCEL SISNIEGA

PAFNUCIO: ¿Cuál?

ANTONIO: Aquella que dice: “Todo le será dado a quien rece con armonía."

PAFNUCIO: ¿Cómo lo sabes?

Antonio: Mi discípulo, Pablo, tuvo una visión.

PABLO: En el cielo vi una cama adornada con velos blancos, y alrededor vi cuatro vírgenes de una luz tan admirable que pensé: Esta gloria sólo puede ser de Dios y del Padre Antonio.

ANTONIO: No soy digno de tanta felicidad.

PABLO: Mientras contemplaba aquella luz resonó en el cielo un clamor divino: "Esta gloria será de Taidé, la meretriz." PAFNUCIO: Alabemos al Señor. Debo visitar a la prisionera.

\section{Celda de Taidé}

Pafnucio enciende la vela que dejara la Abadesa.

124 PAFNUCIO: Hija mía, abre la ventana.

TAIDE: $\quad$ ¿Quién me habla?

PAFNUCIO: ¿Por qué visitas a esta pecadora y le infundes gran alegría?

TAIDÉ: Pafnucio.

PAFNUCIO: Aunque distante, muchas veces pensé en tu salvación. Descríbeme la lucha que sostuviste contigo misma.

TAIDÉ: $\quad$ Sólo puedo decir: no soy digna de Dios.

PAFNUCIO: Nadie lo es.

TAIDÉ: $\quad$ Repasé la totalidad de mis crímenes. Los repasé muy lentamente. $Y$ así como nunca se apartó de mis sentidos el asco ante la inmundicia, así llevo en mi corazón el miedo al castigo eterno.

PAFNUCIO: Mereces el perdón.

TAIDÉ: $\quad$ Si Dios quiere. 


\section{DRAMAS DE HROTSVITHA}

PAFNUCIO: Dame la mano. Ya puedes salir.

TAIDÉ: $\quad$ Venerable Pafnucio no me saques de la suciedad, porque es el lugar más apropiado para mis faltas.

PAFNUCIO: Tu penitencia fue aceptada. Manténte firme y persevera en el amor.

TAIDÉ: $\quad$ ¡Ah! Si no fuera condenada. Si ardiera en un fuego menos terrible.

PAFNUCIO: La gracia no sería don divino si tan sólo se concediera por los méritos de cada uno.

TAIDÉ: Cielo, tierra, viento y animales, alaben todos al Señor. Él sufre con los pecadores y premia al penitente.

PAFNUCIO: Entre el perdón y la espada, prefiere el perdón.

TAIDÉ: $\quad$ Pafnucio acompáñame, consuélame en la hora de mi separación.

PAFNUCIO: No me apartaré de ti hasta ver como tu alma bate sus alas sobre el éter, y haya yo entregado tu cuerpo a la sepultura.

TAIDÉ: Ha llegado. Empiezo a morir. Creador, ten piedad de mí. Llama de regreso al alma que me diste.

PAFNUCIO: Que el alma de este ser, creado de la nada, se una al gozo celestial y su cuerpo sea acogido en el seno de la tierra hasta el día en que, ceniza animada por el soplo perenne, Taidé resucite íntegra y ocupe su lugar en el rebaño de cándidas ovejas. Por los siglos de los siglos, amén...

(Taidé muere. Pafnucio se aleja. La vela queda encendida al fondo del escenario) 